\title{
Transforming Usual Consumers into Prosumers with the Help of Intellectual Capital Collaboration for Innovation
}

\author{
Monica Izvercian, Sabina Alina Şeran, and Cella-Flavia Buciuman
}

\begin{abstract}
In an extremely competitive global market companies strive for supremacy. The goal is to differentiate from competitors and the key element for success is innovation. But how to innovate in an always changing environment? How to maintain market position with such demanding, price sensitive and informed customers? It seems almost impossible. But nothing is impossible when organizations are making use of their main competitive advantage, their intellectual capital, for transforming passive consumers into prosumers. Prosumers are creative individuals who have a predilection for engaging in activities concerning firms or institutions with which they have a relationship with. They are valuable assets if fully engaged with a company. Therefore, the authors argue that human capital can stay in touch through structural capital with consumers and develop a consumer capital - a relationship with them. If this activity is creative and engaging, a number of consumers can change and become prosumers, providing feedback, creative ideas and information for innovation. Alongside prosumers companies can co-create value which differentiates their offer from competition and establish a relationship of trust and involvement which determines consumer recommendations and influence in the market. The proposed interrelated system can be managed with the scope of transforming consumers into prosumers for innovation purposes.
\end{abstract}

Index Terms-Co-creation of value, collaborative innovation, intellectual capital, prosumer.

\section{INTRODUCTION}

The new millennium has brought numerous changes into society. The technology driven economy, the globalisation and the harsh competition between companies developed an enhanced need for innovation. But how to be different, how to defend market position, how to innovate faster than the competition? Usually companies have access to the same resources, technology and environmental factors; their only differentiation lies in their intellectual capital. This asset offers a competitive advantage because it produces value. And this value is active and transformational, because as [1] envisage "a firm is not a passive repository of knowledge; multiple knowledge nodes of the firm interact and recombine with each other with varying intensity, get converted from one form to the other and mobilize, recombine and transform

Manuscript received February 27, 2013; revised April 30, 2013. This work was partially supported by the strategic grant POSDRU 10/1.5/S/77265), inside POSDRU Romania 2007-2013 co-financed by the European Social Fund - Investing in people.

Monica Izvercian, Sabina Alina Seran, and Cella-Flavia Buciuman are with the Politehnica University of Timisoara, 300006 Timisoara, Romania (e-mail: monica.izvercianu@mpt.upt.ro, seran.sabina@yahoo.com, cella.buciuman@mpt.upt.ro). the resources of the firm so as to add value. What results from these re-combinations and conversions is the new knowledge - as organizational learning and/or innovation". This intellectual capital uses and transforms resources in market outputs, drawing the line between success and failure. And success is achieved when the three intellectual capital's components work together: the human capital, the structural or organizational capital and the customer capital.

The present article proposes a new strategy for reaching innovation and relational market outputs through intellectual capital enhancement with the help of a surprising market actor: the prosumer. Prosumers re-emerged from the agricultural era [2] with the Internet boom and the Web2.0 which "facilitates the implosion of production and consumption", being the "prevalent location for consumption, the most important facilitator as a means of prosumption" [3]. But what does prosumption really mean? "The new consumer that participates in processes of production has been called prosumer by consumption scholars" [4]. Also it was seen as a phenomenon, "bringing the blurring gap between producers and consumers to a new point where customers participate in the creation of products in an active, personal and ongoing way" [5]. There have been indeed many ideas about this new market actor both in literature and practice, but its role remained unclear for corporate needs. The authors tried to explain the term and analyze how a firm should relate to it. Therefore because prosumers are empowered consumers, they entail creative engagement characteristics very useful for corporate objectives. They are the new generation of consumers: knowledgeable, digital users, who employ technologies for collaboration or participation in product or service conception, design, testing and who have a certain impact on their social network [6]. But not all technology savvy consumers are necessarily prosumers. For a consumer to become prosumer he or she needs an intrinsic motivation to act, to exceed his or her traditional role and start creating a new output. That motivation is the key for prosuming and it can be used by the company for determining collaboration and co-creation of value. With the help of a collaborative targeted strategy based on the author's proposed transformational model, organizations can profit from prosumer's revolutionizing thinking and generate together innovation in all corporate areas.

\section{INTELLECTUAL CAPITAL CLASSIFICATION AND INTERACTIVITY}

[7] is the first to clearly define intellectual capital as "intellectual material - knowledge, information, intellectual property, experience that can be put to use to create wealth". 
TABLE I: LITERATURE REVIEW FOR INTELLECTUAL CAPITAL'S COMPONENTS

\begin{tabular}{|c|c|c|c|}
\hline Authors & Human Capital & Structural Capital & Customer Capital \\
\hline $\begin{array}{l}\text { Stewart } \\
(1997,2003) \\
{[7] /[8]}\end{array}$ & $\begin{array}{l}\text { thought to be the knowledge of a } \\
\text { workforce } \\
\text {-consists of skills, competences and } \\
\text { abilities of individuals and groups } \\
\text { e.g. the training and intuition of a } \\
\text { team who discovers or improves a } \\
\text { procedure/ } \\
\text { product. }\end{array}$ & $\begin{array}{l}\text { represented by the electronic network } \\
\text { that transports information at a light } \\
\text { speed trough a company, so that it can } \\
\text { react to the market faster than its rivals } \\
\text { comprises knowledge assets that are } \\
\text { company property: patents, copyrights } \\
\text { and trademarks; processes, } \\
\text { methodologies, models; documents and } \\
\text { other knowledge artefacts; computer } \\
\text { networks and software; administrative } \\
\text { systems; and so forth. }\end{array}$ & $\begin{array}{l}\text { depicts the collaboration/shared } \\
\text { learning between a company and its } \\
\text { customers, which forges a bond } \\
\text { between them and brings the } \\
\text { customer back again and again } \\
\text { is the value of relationships with } \\
\text { suppliers, allies, and customers. Two } \\
\text { common forms are brand equity and } \\
\text { customer loyalty. }\end{array}$ \\
\hline $\begin{array}{l}\text { Bontis and } \\
\text { Fitz-Enz } \\
(2002) \\
{[1]}\end{array}$ & $\begin{array}{l}\text { considered to be the knowledge, } \\
\text { talent and experience of employees }\end{array}$ & $\begin{array}{l}\text { describes the codified knowledge bases } \\
\text { that do not exist within the minds of } \\
\text { employees } \\
\text { e.g. databases, filing cabinets, } \\
\text { organizational routines }\end{array}$ & $\begin{array}{l}\text { considered relational capital } \\
\text { represents the knowledge embedded } \\
\text { in the organizational value chain, that } \\
\text { is, the knowledge embedded in the } \\
\text { relationships that the firm has with } \\
\text { suppliers, customers and any entity } \\
\text { outside the boundaries of the firm }\end{array}$ \\
\hline $\begin{array}{l}\text { Chen, Zhu and } \\
\text { Xie (2004) } \\
\text { [9] }\end{array}$ & $\begin{array}{l}\text { refers to factors as employees' } \\
\text { knowledge skill, capability, and } \\
\text { attitudes in relation to fostering } \\
\text { performances which customers are } \\
\text { willing to pay for and the company's } \\
\text { profit comes from. }\end{array}$ & $\begin{array}{l}\text { deals with the mechanism and structure } \\
\text { of an enterprise that can help support } \\
\text { employees in their quest for optimum } \\
\text { intellectual performance, and the overall } \\
\text { business performance can thereupon be } \\
\text { achieved. }\end{array}$ & $\begin{array}{l}\text { considered market capital } \\
\text { and acts as a bridge and a catalyst on } \\
\text { the operations of intellectual capital, } \\
\text { is the main requirement and } \\
\text { determinant in converting intellectual } \\
\text { capital into market value and } \\
\text { thereupon organization business } \\
\text { performance. }\end{array}$ \\
\hline
\end{tabular}

He also opinions that this intangible asset "is hard to identify and deploy effectively, but one you find it, you win". Thus we agree with him that "managing intellectual capital should be business's first priority" because it is the main creator of wealth. If the human capital does not possess the knowledge to properly use a tool, that resource is worthless. Without procedures and programs that enhance the delivery of goods and services the employees are not producing value. And with a weak relational capital all the other two capitals are working in vain. Therefore we can see a strong bound between the three main intellectual capital components.

These three components are presented in Table 1 as they are seen from the scientific literature.

After the literature review we can conclude that human capital refers to employee capabilities to create value in an organization, structural capital summarizes organizational philosophy, structure, systems, processes and intellectual properties - "what remains in the company when employees go home for the night" [10], and customer or relational capital represents the relationships with relevant stakeholders These components are interrelated and they cannot exist one without the other. For example, human capital can convert knowledge into market value using structural capital and facilitated by customer capital. The same way, structural capital needs human capital for enabling enterprises to develop customer capital. And customer capital rests on human and structural capital working together.

But this three component-base structure presented by scholars of the intellectual capital is "static and holistic. It does not show us how we can enhance the value of this potential capital and how we can transform it in action and value" [11]. Accordingly, we envisaged the opportunity of today's socio-economic, technological and cultural context for transforming usual consumers into prosumers due to intellectual capital component's interactive collaboration for innovation-driven results. In this manner we generate flow to the innovative process and we engage all intellectual capital potential towards this objective.

\section{Prosumer Tran for Mation Model for COLLABORATIVE INNOVATION}

Intellectual capital must behave as an active, performing living mechanism for the creation of innovation. With this purpose in mind, its components ought to collaborate and interact in a perfect symbiosis. According to [12] - the open innovation paradigm developer, "firms should use external ideas as much as internal ones and internal and external ways to penetrate the market, while improving their technology". His idea is envisaging the fact that human, structural and relational capital are not complete, they lack an external partner for an efficient and rapid innovation process. The authors suggest that the external partner should be attracted into the co-creation process for innovative results. This way, we raise the bar for competitors, improving the organizational outputs and speeding up the innovation process. But the next question emerges: who has all the attributes for linking the three intellectual capital components together in a stable and fruitful manner? Which market actor is creative and sufficiently motivated to direct the added value out of this coupling towards the corporate process management? Prosumers have all the above mentioned competences, because they are eager to engage, malleable to be transformed and creative enough to produce valuable outcomes.

Prosumers in fact are originating from usual consumers who become empowered and aware of their worth. Therefore, a company needs to find a way to engage and motivate its consumers to become prosumers and afterwards guide them for a fully transformation process in which they 
internationalize the organizational culture and become part of it. This special relationship takes time and effort but it's very rewarding. In a changing environment, in which price and information rule, a company that is transforming its customers into prosumers for own benefit will gain much more than a satisfied consumer. The specific company will increase its customer retention rate, profitability score, and lifetime value and will become more visible and trustworthy for the attraction of new customers. Withal, the transposing value of this co-creation will increase market share and competitive position due to cost-effective $R \& D$ and rapid implementation of innovation.

In Fig. 1 we present the process of transforming customers into prosumers and integrating them into a successful innovation model. This model stipulates a win-win relationship. The company is innovating alongside its customers in a time and cost saving manner with a positive impact on its global image and the consumer has the satisfaction of being listened at, important for the society, contributing to the community and growing in personal value.

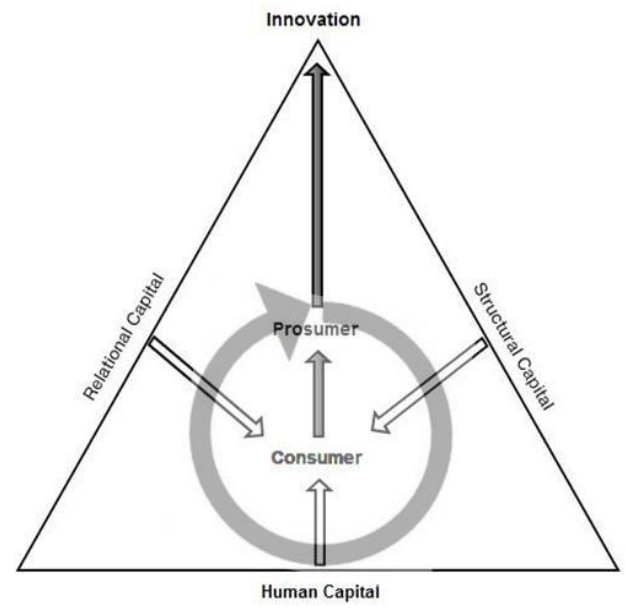

Fig. 1. Prosumer transformation model for innovation.

For a thorough understanding of the interactivity of the original three components that can lead towards customer transformation we need to analyse their inner composition. Therefore, we take into account the work of [9] who tried to evaluate intellectual capital based on specific indices of each component amending in the same time the relevant qualities prior to prosumer conversion. The result of this process can be seen in Fig. 2 below.

Human capital refers to employees and the most important elements are the employees' abilities and the relationship the company develops with them. These two main subcomponents enhance the organization value and contribute to the customer transformation into a real prosumer.

An employee who is content with its status and is motivated by the corporate culture to share his ideas will convey creative output. As seen before, human capital cannot succeed without an adequate structural capital and especially a corporate culture. This assembly of values, visions, norms, beliefs and behaviours have the power to restrict employees' openness to knowledge sharing and external communication as well. Instead, if the organizational culture supports creativity, customers will be stimulated to contribute and engage. The manager's philosophy is critical in this situation because he can lean towards transparency and accept change or limit organizational growth through bureaucratically thinking. The culture and managerial philosophy is advised to encourage organizational learning which translates into employee continuous learning motivation and constantly renewal of ideas and management procedures.

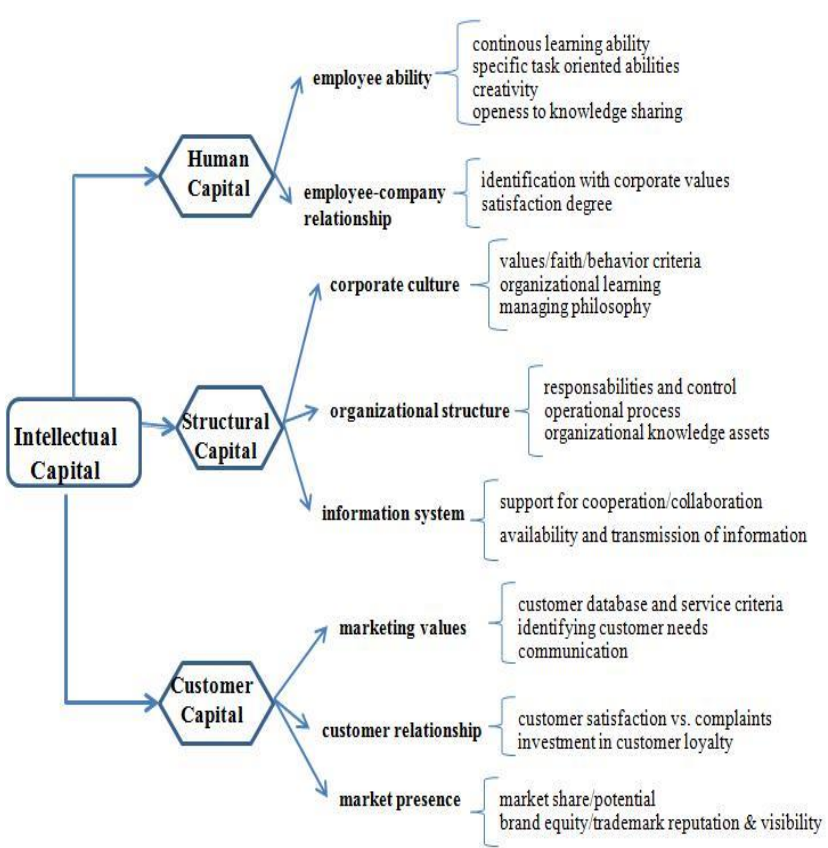

Fig. 2. Intellectual capital components for prosumer co-creation.

The operational process must be constantly controlled and evaluated for a clear image of the best procedures in this direction because the organizational power lays in its structure, operational process and none of the less in its knowledge assets- its previous innovations. Past experiences with innovative outputs can trigger new creative ideas which must be sustained by the information system, a basic element for knowledge sharing and external communication. The interactivity of both the human and the structural capital enables coordination and the cultivation of customer capital. This capital oriented towards the market behaves as a bridge between the internal values and the external requirements. It converts intellectual capital into market value and measures the business performance through customer databases and customer satisfaction rates. But also, customer capital orients employees and managers towards best practices in investing and managing customer loyalty through interactive communication and rapid solving of complaints. The corporate image on the market plays an important role in determining customer engagement decision. If the company is unknown or has a bad reputation no one will be receptive to its communication and involvement strategy. Brand equity is "the value (positive or negative) that a brand adds to an organisation's products or services" [13], it manifests into long-term loyalty and results in market share gains. It describes how customers relate to a brand, how they pay for the respectively product or service and become unpaid ambassadors for the company. This market presence asset is very valuable and therefore must be carefully managed by both human and structural capital. The previous innovations 
can built this reputation and it can be maintained by the human capital's actions.

A customer who is satisfied and appreciates the brand, motivated with the help of the information system and by the corporate values which transpose through employees' communication and behaviour will certainly have all the premises for transforming into a fully engaged prosumer. And this prosumer will link the three intellectual capital components together in a beautiful symbiosis for co-creating innovation and positive word-of-mouth.

\section{EXAMPLES OF THE PROSUMER-ORIENTED MODEL FOR COLLABORATIVE INNOVATION}

Prosumer-oriented co-creation models are today more visible than ever. Let's take for example Westpac, an Australian bank analysed by [7]. At the beginning of the 90's it undertook a new strategic change, based on customer evaluation. Their customer database (customer capital) was working together with the information system (structural capital) which was transmitting information to the management department (human capital). This operational process revealed some customers who were not profitable. The bank decided to focus on their needs and together with them to find solutions that would add value to the relationship. This joint invest in the value of the relationship was profitable for the bank which was not afraid to share information with its customers and ask for help. In a theoretical explanation this process transformed the bank customers into prosumers who engaged in the collaboration and brought important gains. In this case they did not cause innovation but in a certain way influenced a new innovative organizational culture.

Facebook is such an illustrative example of prosumers becoming involved by and with a company's intellectual capital for innovative outcome. The creator of the Facebook (human capital) was creative enough and open-minded to build a social network (structural capital) that had a winning mixture: it was converting intellectual capital into market value (customer capital) by involving customers into the experience. These customers were free to use the platform and add value to it in a co-creation way. The innovation appeared once prosumers were discovering new uses for the platform, moving away from just finding relatives through the web to connecting with them in engaging ways, promoting social-oriented campaigns or even sharing information, cooperating at a global level. Enterprises found a fast way to become visible in the online environment with the help of Facebook and this interactive collaboration brought worldwide power and influence to a social network developed at first just for Harvard university students.

Wikipedia or Linux are the stars of open innovation and prosumer initiative enabling platforms. Their example is studied even today for the scope of discovering their business model secrets for success. The authors suggest that the prosumer transformational model with the help of intellectual capital component's collaboration may have the answer. Jimmy Wales and Larry Sanger at the beginning of this century launched the free encyclopaedia called Wikipedia. The founder's creativity (human capital) and open-minded approach - the open platform (structural capital) provided a new philosophy (structural capital) of collective commons: everyone can contribute personal knowledge to the society. Their appeal was extremely successful and the reason lies in the approach. They have built a phenomenon, a prosumer-oriented phenomenon. Their intellectual capital worked in a perfect symbiosis enabling customers to reach a prosumer status. And the innovation immediately followed. Consumers started to use Wikipedia also as a news source enhancing its usability. The consumer capital (reputation in particularly) is the main attraction for new prosumers, the process is continuous and very interactive. The already registered consumers have the possibility to always stay informed (through the structural capital) about new posts on their favourite pages and intervene if considered necessary. All intellectual capital's components together with prosumers are shaping a new business rule: "harness the new collaboration or perish" [5]. Therefore firms need to develop trust based relationships with their consumers and transform them in external collaborators.

Lays is one of the companies that embraced without even knowing that, the prosumer mentality. They are usually organizing crowdsourcing campaigns all over the world. Crowd sourcing is especially effective in the B2C area where it is focused "on building something together with customers instead of simply outsourcing tasks to them, thus aiming to strengthen their ownership and loyalty for the company/brand in question" [14].Therefore the professionals (human capital) of Lays India developed in 2009-2010 a campaign called "Give Us Youd Dillicious Flavor" (http://pepsicoindia.co.in/media/Press-Releases/release_05_ 04_10.aspx), as a contest where its customers were empowered to propose and choose a new flavour for Lays potato chips. The contest was promoted accordingly (customer capital) and lasted eight months while consumers could register and upload their personal ideas for Lays flavours on the company's website (structural capital). In January 2010 a commission of PepsiCo judges selected four wining flavours from a total of 1.3 million proposals. These four flavours were physically realized and launched on the market leaving the reaction to the customers who voted summarizing in total approximately 15 million votes the winning flavour. The person that proposed the idea was rewarded with $120.000 \$$ and $1 \%$ of the sales profit of his product. In the end the company gained a good market positioning, visibility and customer loyalty and the prosumers were offered the choice of being creative and of choosing the winning flavour as desired. Due to a perfect collaboration between the three intellectual capital components (corporate professional, web platform and marketing value of the campaign) customers were transformed into prosumers because they were motivated to expand their traditional role and were free to develop their creative mind. The result: prosumers brought innovation $-\mathrm{a}$ new Lays flavour, together with positive word-of-mouth and they assured a wonderful promotion for the brand.

The examples could continue, but the important aspect we need to remember is that prosumers are valuable assets for a companies and all the organizational attributes must work together to assure their emergence for innovative outputs. 


\section{CONCLUSION}

Either if organizations are built with this new mentality like the example of Twitter, YouTube, Second Life or if they are just using the prosumer-oriented approach for specific campaigns as Lays, Coca-Cola, Dr. Pepper and many others, either way, they must be aware of the importance and improve their intellectual capital components' collaboration. The managers must understand the depth of and pay special attention to the human, structural and relationship capitals for directing them towards customer transformation. Each subcomponent presented in this paper has a role and an influence in prosumer motivation.

The strategy for transforming customers into fully engaged prosumers has as main focuses: the human capital management towards creativity and openness, the structural capital enhancing customer empowerment, and customer capital communication of knowledge sharing, organizational transparency, and external collaboration desire. Practical suggestions in this sense are centred on finding ways to:

1) Engage employees in the open innovation strategy by trainings (continuous learning), minimizing the fear of change, enhancing creativity and inspiring them to freely communicate their suggestions, propositions. They must be connected to the corporate mission and vision, to the company's culture and to internalize the organizational philosophy in such a way as to believe and live it day by day.

2) develop an operational process and culture that translates into an adequate information system which has the possibility of both synchronous and asynchronous communication, offers continuous feedback through Web 2.0 applications (e.g. blogs, wikis, collaboration tagging systems), supports co-creation of ideas (e.g. virtual concept mapping tools, virtual whiteboards) and allows visualization and organization of information.

3) Improve the agility and flexibility of the enterprise by measuring customer satisfaction, managing customer databases and especially correlating human and structural capital for promoting a good organizational image which will furthermore attract new customers.

4) Motivate and engage customers in the corporate activity by empowering them to participate and build together a new or better version of the current organizational or market offer.

In conclusion, today's reality leads companies to radical transformations in their inner core values and structure. Regardless of service or product specialization, of industry area and dimension, physical or virtual location of activity, each organization can develop a prosumer transformation model and transpose it into their marketing strategy. Future studies in this direction envisage the measurement of the model's impact on several companies, with a special emphasis on the structural capital's collaboration tools needed for prosumer engagement.

\section{ACKNOWLEDGMENT}

This work was partially supported by the strategic grant POSDRU 10/1.5/S/77265), inside POSDRU Romania
2007-2013 co-financed by the European Social FundInvesting in people.

\section{REFERENCES}

[1] N. B. Bontis and J. F. Enz, "Intellectual capital ROI a causal map of human capital antecedents and consequences," Journal of Intellectual Capital, vol. 3, pp. 223-247, 2002.

[2] A. Toffler, "The Third Wave," Bantam Books, 1980.

[3] G. Ritzer and N. Jurgenson, "Production, Consumption, Prosumption: The nature of capitalism in the age of the digital prosumer," Journal of Consumer Culture, vol. 10, no. 1, pp. 13-36, 2010.

[4] V. Lehdonvirta, "A History of the Digitalization of Consumer Culture: From Amazon through Pirate Bay to FarmVille," in Pre-print version of a chapter in Digital Virtual Consumption, J. Denegriknot and M. Molesworth, ed., Routledge, 2012.

[5] D. Tapscott and A. D. Williams, Wikinomics: How Mass Collaboration Changes Everything, USA: Portfolio, 2008.

[6] M. Izvercianu and S. Seran, "Defining and involving the virtual prosumer through participative marketing strategies in the mpt master program," in Proc. RMEE Conf., 2011, Cluj Napoca.

[7] T. A. Stewart, Intellectual Capital, The New Wealth of Organizations, Currency Doubleday, USA, 1997.

[8] T. A. Stewart, The Wealth of Knowledge: Intellectual Capital and the Twenty-First Century Organization, New York: Doubleday, 2003.

[9] J. Chen, Z. Zhu, and H. Y. Xie, "Measuring intellectual capital: a new model and empirical study," Journal of Intellectual Capital, vol. 5, no. 1, 2004, pp. 195-212

[10] G. Roos, J. Roos, L. Edvinsson, and N. C. Dragonetti, "Intellectual capital-Navigating in the new business landscape," New York: New York University Press, 1997.

[11] A. Curaj and I. Jianu. (2008). Organizational Intellectual Capital. [Online]. Available: http://www.knowledgedynamics.ro/.

[12] H. Chesbrough, Open Innovation: The New Imperative for Creating and Profiting from Technology, Boston: Harvard Business School Press, 2003.

[13] B. Marr, "Key Performance Indicators," The 75 measures every manager needs to know, Harlow, UK: Pearson Education Limited, 2012.

[14] S. Viitamaki, "The flirt model of crowdsourcing, planning and executing collective customer collaboration,” Marketing Master Thesis, Helsinki School of Economics, Spring, 2008.

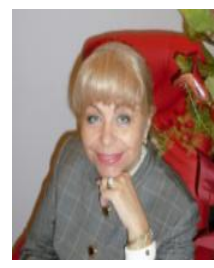

Monica Izvercian was born in Sibiu, in 1948, who has a bachelor degree in Constructions at the Traian Vuia Polytechnic Institute, Romania from 1971, where she continued her educational path becoming an Assistant Professor in 1973 and an Associate Professor in 1992 After certain specialization courses abroad, in 1997 she becomes Professor and dean at the Management in Production and Transportation Faculty of Polytechnic University of Timisoara. Prof. Monica Izvercian current interest is in management and marketing, with several research projects, books and over 150 international scientific publications.

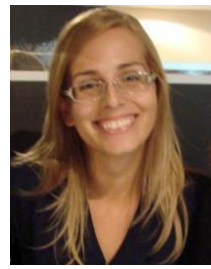

Sabina Alina Seran was born in Arad, on June 3, 1985 , who has a bachelor degree in Comunication and Public Relations and an MBA at The Polytechnic University of Timisoara, Romania in 2008, respectively in 2010 . Presently she works as a PhD student in marketing at the Polytechnic University of Timisoara developing prosumer-oriented marketing strategies for Romanian companies. During her studies she published 10 scientific articles at management international conferences.

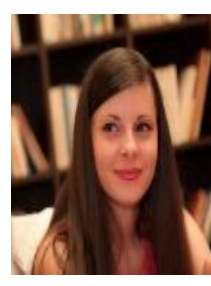

Cella-Flavia Buciuman was born in Timisoara, on July 27, 1984, who has a bachelor degree in Automatics and Computer Science since 2008 and, a Master degree in Business Administration at Polytechnic University of Timisoara, since 2010. Currently she is an Assistant Professor at Polytechnic University of Timisoara, Faculty of Management in Production and Transportation and also a PhD Candidate in the field of Engineering and Management. Her main interests are related to agile methodologies, agile marketing, measuring marketing performance and social media marketing. 